\title{
Time Dependence of $\mathrm{Li}^{+}$Action on Acetylcholinesterase Activity in Correlation with Spontaneous Quantal Release of Acetylcholine in Rat Diaphragm
}

\author{
Panagiota Kouniniotou-KrontiRI and Stylianos TSAKIRIS \\ Department of Experimental Physiology, University of Athens, \\ Medical School, P.O. Box 141 85, GR-115 10 Athens, Greece
}

\begin{abstract}
The mean miniature end-plate potential (m.e.p.p.) frequency and the acetylcholinesterase (AChE) activity have been examined in the rat diaphragm, in relation to the time of $\mathrm{Li}^{+}$action. Substitution of $\mathrm{LiCl}$ for $\mathrm{NaCl}$ caused increase in m.e.p.p. frequency, the final level of which depended on $\mathrm{Li}^{+}$concentration in the bath solution. Incubation of diaphragm homogenate with $\mathrm{NaCl}$ caused initially a slight increase of AChE activity, reaching a plateau after $20 \mathrm{~min}$. Substitution of $\mathrm{LiCl}$ for $\mathrm{NaCl}$ produced an increase in $\mathrm{AChE}$ activity to a maximum, followed by a decrease to a minimum. The activity consequently returned to a steady level. During complete substitution of $\mathrm{LiCl}$ for $\mathrm{NaCl}$, the maximum value of AChE activity coincided with the maximum m.e.p.p. frequency $\left(F_{\max }\right)$ induced by $\mathrm{Li}^{+}$; the minimum value correlated with the precise instant that the frequency reached a plateau. The addition of prostigmine caused: a) blockade of AChE activity, and b) prostigmine concentration-dependent decrease of $F_{\max }$ and/or disappearance of m.e.p.p.s from neuromuscular junctions treated with $\mathrm{Li}^{+}$. These results are discussed in terms of correlation between changes of AChE activity induced by $\mathrm{Li}^{+}$and variations of spontaneous quantal release of the transmitter from nerve terminals of the rat diaphragm treated with $\mathrm{Li}^{+}$.
\end{abstract}

Key words: lithium, acetylcholinesterase activity, miniature end-plate potential frequency.

It is almost 40 years since CADE (1949) rediscovered the therapeutic properties of $\mathrm{Li}$ in the treatment of manic excitement, and $\mathrm{Li}$ salts are now firmly established in modern psychiatric treatment. Since OvERTON (1902) first showed that muscle retained its excitability in $\mathrm{Li}$ solution, there has been much interest devoted to the effect of $\mathrm{Li}^{+}$on the electrical properties of excitable cells. It was found that the action potential is little affected when the $\mathrm{Na}^{+}$of the external solution is replaced by $\mathrm{Li}^{+}$(Hodgkin and Katz, 1949; HuXley and STÄMPfli, 1951) and the $\mathrm{Na}^{+}$

Received for publication September 26, 1988 
channel of the action potential discriminates poorly between these cations (Chandler and Meves, 1965). According to these results, $\mathrm{Li}^{+}$action on the nervous system, in the low therapeutic concentrations (about $1 \mathrm{~mm}$ ), could not be caused by alteration of the conduction process of central neurons.

However, the same low concentrations of $\mathrm{Li}^{+}$could influence the mechanisms of synaptic transmission. Thus the effect of $\mathrm{Li}^{+}$on transmitter release or generally on the synaptic transmission has been studied by many authors (ONODERA and YamaKawa, 1966; Kelly, 1968; Crawford, 1975; Ortiz and Junge, 1978; KOUNINIOTOU-KRONTIRI, 1985a).

It has recently been shown that $\mathrm{Li}^{+}$and $\mathrm{Na}^{+}$differentially change the activity of acetylcholinesterase (AChE) of the rat diaphragm by interacting with the enzyme (KoUNINIOTOU-KRONTIRI and TSAKIRIS, 1984), while $\mathrm{Li}^{+}$may neutralize negative charges of AChE more successfully than does $\mathrm{Na}^{+}$, resulting in higher activity, stabilization, and cooperativity of the enzyme (TsakiRIS and KouniniotouKrONTIRI, 1988). Moreover, at optimum $\mathrm{pH}$ the $K_{\mathrm{m}}$ values calculated at high substrate concentrations $(>200 \mu \mathrm{M})$ indicate that substrate affinity of AChE can be increased only by $\mathrm{Li}^{+}$binding on the enzyme while changes in $\mathrm{pH}$ can modulate the cooperativity and may denaturate allosteric sites on the enzyme that bind $\mathrm{Li}^{+}$ (TSAKIRIS and KouNINIOTOU-KRONTIRI, 1988).

The activity of AChE can influence the time course of spontaneous quantal release of acetylcholine $(\mathrm{ACh})$ at the rat neuromuscular junction treated with $\mathrm{Li}^{+}$ (KoUniniotou-KrontiRI, 1985a). Thus, in the presence of prostigmine miniature end-plate potentials (m.e.p.p.s) disappear from the rat neuromuscular junction treated with $\mathrm{Li}^{+}$, following an exponential decrease in frequency, while a steady and high level of m.e.p.p. frequency can be maintained for a long period in the absence of prostigmine.

Since the spontaneous quantal release of $\mathrm{ACh}$ seemed to be correlated to the hydrolysis of the transmitter, possible variations of $\mathrm{AChE}$ activity induced by $\mathrm{Li}^{+}$ as a function of time, could also influence the time course of m.e.p.p. frequency. Therefore, it was considered of interest to investigate whether AChE activity varies in relation to the time of $\mathrm{Li}^{+}$action on the enzyme and to study these changes with respect to the corresponding variations of m.e.p.p. frequency.

\section{MATERIALS AND METHODS}

Electrophysiological experiments were performed on the isolated hemidiaphragm of the rat at $37^{\circ} \mathrm{C}$ and at room temperature $\left(20-23^{\circ} \mathrm{C}\right)$. Standard intracellular recording techniques with $3 \mathrm{M} \mathrm{KCl-filled} \mathrm{microelectrodes} \mathrm{of} \mathrm{tip} \mathrm{resistances} \mathrm{10-15} \mathrm{M} \Omega$ (measured in $3 \mathrm{M} \mathrm{KCl}$ ) were used to record membrane potential and m.e.p.p.s from superficial end-plates of the muscle. The hemidiaphragm was placed in a constant temperature bath and perfused with oxygenated Krebs solution of the following composition (in $\mathrm{mM}$ ): $\mathrm{NaCl}, 115.2 ; \mathrm{KCl}, 5.9 ; \mathrm{CaCl}_{2}, 2.6 ; \mathrm{MgCl}_{2}, 1.2 ; \mathrm{NaHCO}_{3}$, 26.2; $\mathrm{NaH}_{2} \mathrm{PO}_{4}, 1.2 ; \mathrm{Na}_{2} \mathrm{SO}_{4}, 1.2 ;$ glucose, 5.5. In Li-Krebs, 115.2, 86.4, 57.6, 
$28.8,11.5$, or $5.76 \mathrm{~mm}$ of $\mathrm{NaCl}$ were replaced by $\mathrm{LiCl}$. Occasionally, different amounts of prostigmine $(3.0-30.0 \mu \mathrm{M})$ were added to the perfusing solution: a) simultaneously with the substitution of $\mathrm{LiCl}$ for $\mathrm{NaCl}$ or b) $20 \mathrm{~min}$ after the substitution. To avoid fasciculations that appeared at the rat diaphragm after prostigmine addition (mainly with the prostigmine concentration of $3.0 \mu \mathrm{M}$ ), $3.1 \mu \mathrm{M}$ of tetrodotoxin were also added to Li-Krebs solution.

Biochemical measurements were carried out on rat homogenized hemidiaphragm and eel E. electricus pure AChE (Sigma). The hemidiaphragms were placed in a bath, perfused with Krebs solution, and trimmed of connective tissue after washing out the blood from the freshly dissected muscles. Considerable mincing was necessary before homogenizing. The medium of homogenization contained $70 \mathrm{~mm}$ Tris- $\mathrm{HCl}$ buffer, (pH 8.0) and $300 \mathrm{~mm}$ sucrose; $20 \mathrm{mg}$ of tissue $/ \mathrm{ml}$ of medium were disrupted for $8 \mathrm{~min}$ with an Omni mixer and then were homogenized in a Potter-Elvehjem at $4^{\circ} \mathrm{C}$. The protein content of the homogenate was determined accroding to Lowry et al. (1951). AChE activity was determined in the rat homogenized diaphragm and in eel E. electricus enzyme by following the hydrolysis of acetylthiocholine according to the method of ELLMAN et al. (1961).

The incubation mixture $(3 \mathrm{ml})$ contained $50 \mathrm{~mm}$ Tris- $\mathrm{HCl}(\mathrm{pH} 8.0), 240 \mathrm{~mm}$ sucrose and 115.2, 57.6, 28.8, 11.5, 5.76, 1.15, or $0 \mathrm{~mm} \mathrm{NaCl}$ or $\mathrm{LiCl}$. Protein concentration was $300 \mu \mathrm{g} / \mathrm{ml}$ of incubation mixture for the rat homogenized diaphragm and $0.3 \mu \mathrm{g} / \mathrm{ml}$ for the E. electricus enzyme. The incubation was carried out under continuous magnetic stirring. The reaction was initiated after addition of $0.1 \mathrm{ml}$ of 5,5-dithionitrobenzoic acid (DTNB) and $0.05 \mathrm{ml}$ of acetylthiocholine iodide, which was used as substrate. The final concentration of DTNB and substrate were $0.125 \mathrm{~mm}$ and $0.5 \mathrm{~mm}$ respectively. The reaction was followed spectrophotometrically by the increase in absorbance at $412 \mathrm{~nm}$ using a Beckman Acta MVI spectrophotometer and the AChE activity was measured in relation to the time of incubation in the above reaction medium containing 115.2, 57.6, 28.8, 11.5, $5.76,1.15$, or $0 \mathrm{~mm}$ of $\mathrm{NaCl}$ or $\mathrm{LiCl}$. When AChE blocking was necessary, different amounts of prostigmine $(3.0-30.0 \mu \mathrm{M})$ were added to the incubation medium.

\section{RESULTS}

Lithium action on diaphragm AChE activity and ACh spontaneous quantal release

In the experimets shown in Fig. 1, we observed that the incubation with $\mathrm{NaCl}$ $(115.2 \mathrm{~mm})$ of the diaphragm homogenate at $37^{\circ} \mathrm{C}$, caused an initial slight and transitory increase of AChE activity, reaching a plateau after $20 \mathrm{~min}$. In the Krebs solution containing the same concentration of $\mathrm{NaCl}$ the frequency of m.e.p.p.s is steady at about $1.5 / \mathrm{s}$.

The substitution of $\mathrm{LiCl}$ for $\mathrm{NaCl}$ caused also an increase in the enzyme activity until a maximum value was reached, which was followed by a progressive decrease to a minimum one ( $20 \mathrm{~min}$ after substitution). Then the activity increased to return to a steady level, which was higher than the one observed during the incubation 


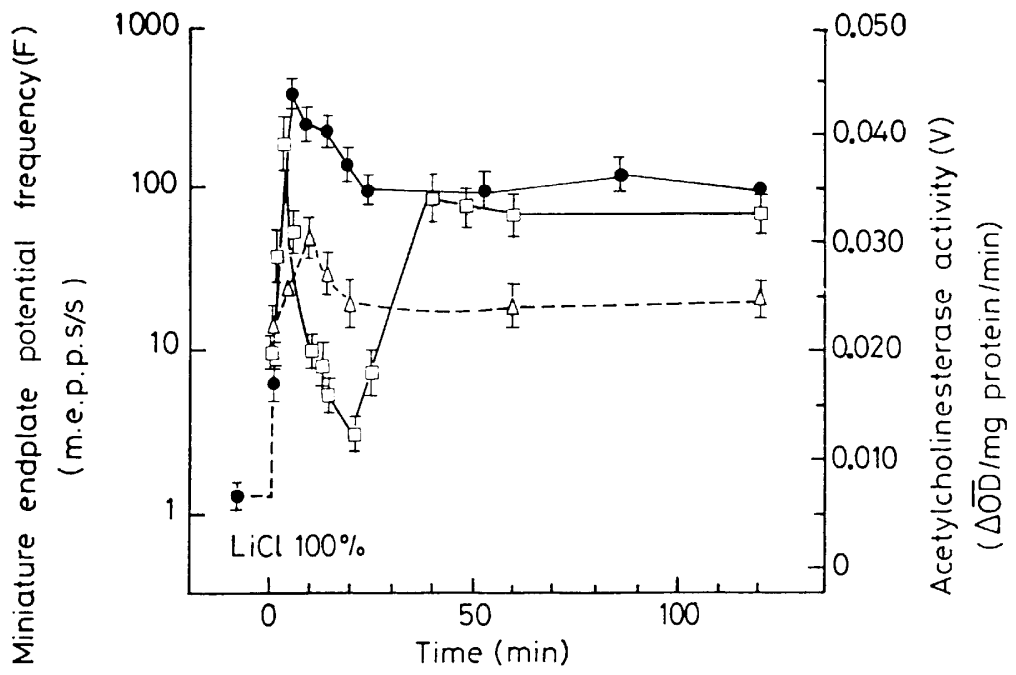

Fig. 1. Effect of $\mathrm{LiCl}(115.2 \mathrm{~mm})$ on m.e.p.p. frequency, $F(\bullet)$, and $\mathrm{AChE}$ activity ( $\square$ ) in the rat diaphragm as a function of time at $37^{\circ} \mathrm{C}$. Abscissa denotes time (min) of $\mathrm{Li}^{+}$action which begins at time zero. The effect of $\mathrm{NaCl}(115.2 \mathrm{~mm})$ on AChE activity as a function of time is also indicated $(\triangle)$. Points and vertical bars represent mean values \pm S.D. Each point concerning AChE activity represents the average value of duplicate determinations from a typical experiment which has been repeated three times. For each mean m.e.p.p. frequency, a minimum number of three experiments has been performed. Note the semilogarithmic coordinates for the changes of $F$ and the linear coordinates for the changes of AChE activity.

of the diaphragm homogenate with $\mathrm{NaCl}$. After the substitution of $\mathrm{LiCl}$ for $\mathrm{NaCl}$, the m.e.p.p. frequency rose exponentially to a maximum. During this phase the m.e.p.p. frequency at any time $\left(F_{\mathrm{t}}\right)$ was given by $F_{\mathrm{t}}=F_{\mathrm{o}} \exp (t / \tau)$, where $F_{\mathrm{o}}$ is m.e.p.p. frequency in Krebs solution (before any substitution) and $\tau$ is a time constant. This increase in m.e.p.p. frequency is consistent with the rise in m.e.p.p. frequency observed by CRAWFORD (1975). Subsequently the m.e.p.p. frequency fell again until a lower final level $\left(F_{\mathrm{f}}\right)$ was reached, which was much higher than the one observed befofe the substitution. The above decline was again an exponential one.

As can be seen in the same figure the initial increase of AChE activity and the rise of m.e.p.p. frequency had almost parallel time courses and their maximum values coincided in time.

Moreover, the decrease of the enzyme activity kept pace with a respective diminution of m.e.p.p. frequency and the minimum value of the activity almost coincided in time with the stabilization of the m.e.p.p. frequency. This steady and high level of m.e.p.p. frequency was maintained for a long period, while the AChE activity progressively rose towards a steady level.

Similar results were obtained also in experiments at $20^{\circ} \mathrm{C}$. However, changes in $\mathrm{AChE}$ activity and m.e.p.p. frequency induced by $\mathrm{LiCl}$ appeared to be greater 


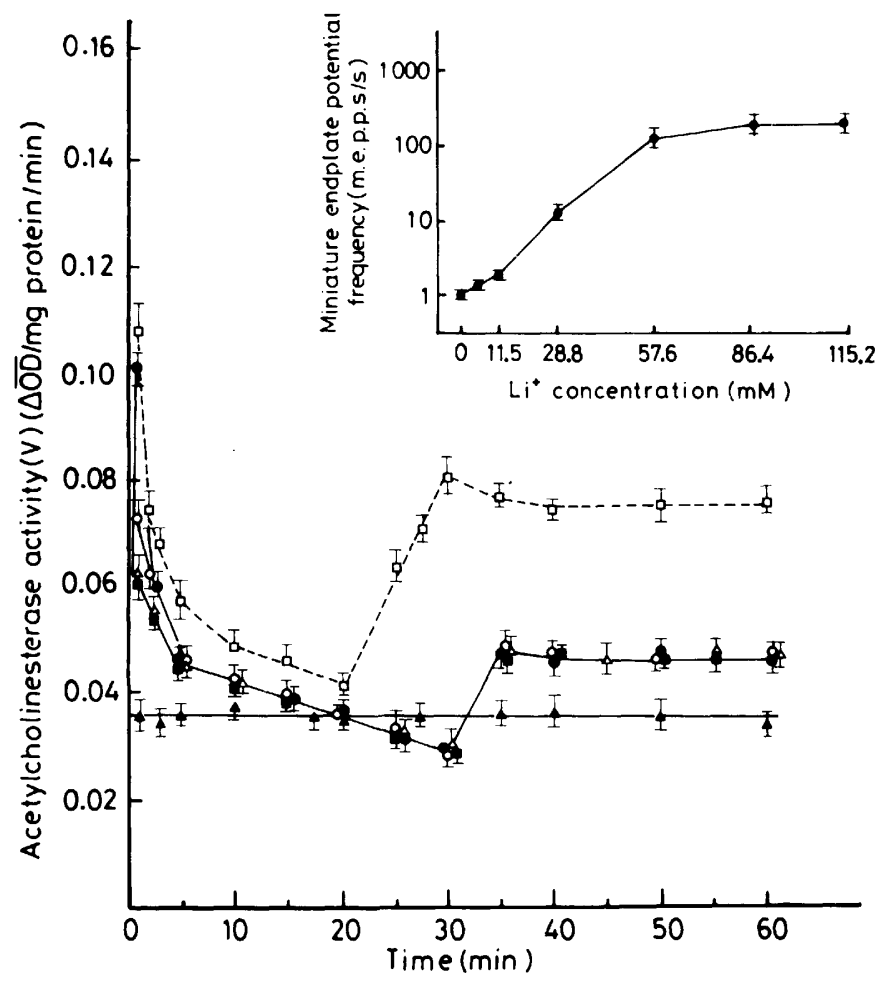

Fig. 2. Effect of different concentrations of $\mathrm{LiCl}(115.2(\square), 57.6(\bullet), 28.8(O), 1.15$ $(\triangle)$, and $0(\Delta) \mathrm{mM})$ on AChE activity in rat diaphragm as a function of time at $37^{\circ} \mathrm{C}$. Inset shows the final frequency ( $60 \mathrm{~min}$ after the substitution) as a function of the concentration of $\mathrm{LiCl}$ in $\mathrm{Krebs}$ solution. For details see the legend to Fig. 1.

and faster at $37^{\circ} \mathrm{C}$ than at $20^{\circ} \mathrm{C}$.

The time course of $\mathrm{AChE}$ activity during incubation of the diaphragm homogenate with different concentrations of $\mathrm{LiCl}(115.2,57.6,28.8,11.5,5.76,1.15$, and $0 \mathrm{mM}$ ) can be seen in Fig. 2. In these experiments we observed that the initial increase of the enzyme activity is dependent on $\mathrm{LiCl}$ concentration only in high concentrations $(>11.5 \mathrm{~mm}$ ) while $1.15 \mathrm{~mm}$ of $\mathrm{LiCl}$ has the same efficacity as 5.76 or $11.5 \mathrm{~mm}$. The minimum and the final activities of AChE were higher and appeared earlier in the presence of $115.2 \mathrm{mM}$ of $\mathrm{LiCl}$ while the curve of the enzyme activity was the same for the concentations of 57.6, 28.8, 11.5, 5.76, and $1.15 \mathrm{~mm}$ after the fifth minute of incubation. The action of $\mathrm{NaCl}$ on $\mathrm{AChE}$ activity (initial and transitory increase reaching a plateau) was concentration dependent while $1.15 \mathrm{~mm}$ of $\mathrm{NaCl}$ had no effect on the activity of the enzyme. In the absence of cations there was no change of AChE activity as a function of time. The inset in Fig. 2 shows the m.e.p.p. frequency after $60 \mathrm{~min}$ (final level) of complete or partial substitution of $\mathrm{LiCl}$ for $\mathrm{NaCl}$. 
Effect of prostigmine on diaphragm AChE activity and spontaneous quantal release of ACh during lithium action

In the present work, prostigmine was added in order to study whether a blockade of $\mathrm{AChE}$, at different phases of $\mathrm{Li}^{+}$action, can influence m.e.p.p. frequency; therefore different amounts of prostigmine were added at the same time with $\mathrm{LiCl}$ or 20 min after the substitution of $\mathrm{LiCl}$ for $\mathrm{NaCl}$.

After AChE blocking with prostigmine, we did not observed any change, in acetylthiocholine hydrolysis, induced by $\mathrm{Li}^{+}$as a function of time. It should be noted that AChE activity of the rat diaphragm homogenate disappeared more rapidly when prostigmine was added at the beginning of the experiment (simultaneously with $\mathrm{LiCl}$ ) and more progressively when the same anti-AChE was added to the medium after $20 \mathrm{~min}$ of $\mathrm{Li}^{+}$action. The time of the enzyme inactivation was also dependent on prostigmine concentration. Figure 3 shows the decrease of total $\mathrm{AChE}$ inactivation time, in relation to prostigmine concentration, when $\mathrm{LiCl}$ and prostigmine were added simultaneously. Under these experimental conditions the time of $50 \%$ inhibition of the enzyme was also dependent on the concentration of prostigmine (Fig. 3, inset).

The effect of prostigmine on m.e.p.p. frequency during $\mathrm{Li}^{+}$action was also studied. Figure 4 shows that the addition of prostigmine $(30 \mu \mathrm{M})$ in Krebs solution, 20 min after substitution of $\mathrm{LiCl}$ for $\mathrm{NaCl}$, caused (at $37^{\circ} \mathrm{C}$ ) m.e.p.p. disappearance from the rat neuromuscular junction treated with $\mathrm{Li}^{+}$, following an exponential

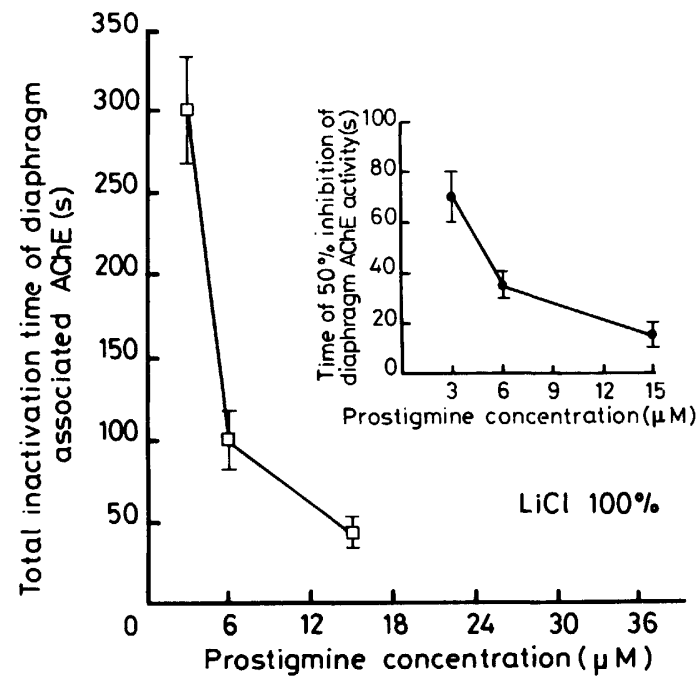

Fig. 3. Total inactivation time of diaphragm-associated AChE as a function of prostigmine concentration. The experiments were performed at room temperature and prostigmine was added to the incubation medium simultaneously with $\mathrm{LiCl}$ (115.2 mM). Inset shows the time of $50 \%$ inhibition of the diaphragm AChE activity under the same conditions. More details are given in the legend to Fig. 1. 


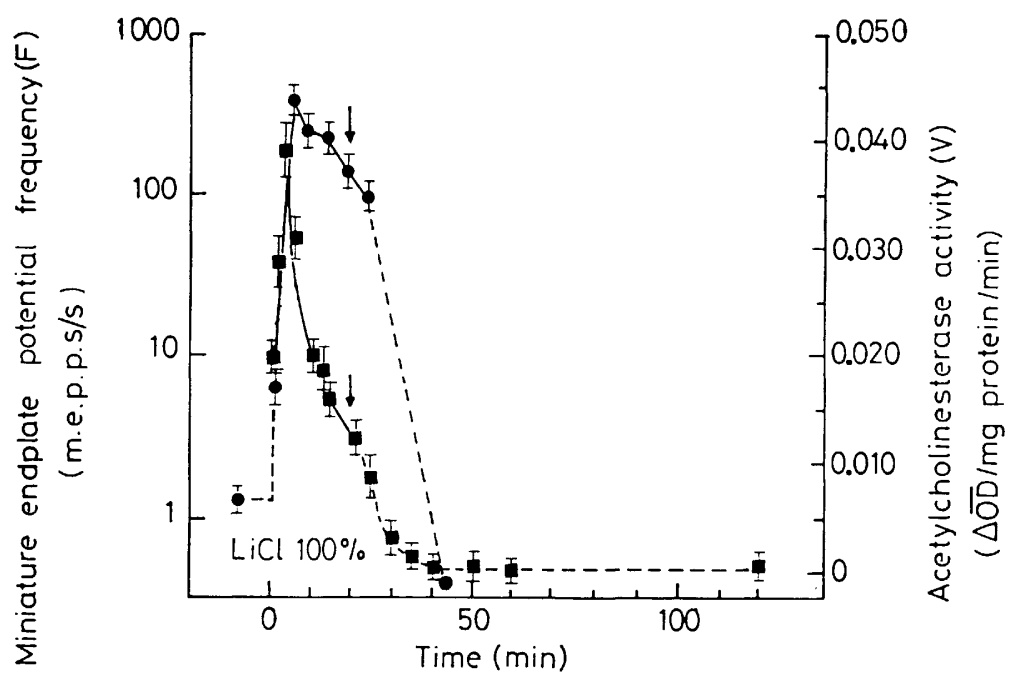

Fig. 4. Effect of $\mathrm{LiCl}$ and prostigmine on m.e.p.p. frequency, $F(\bullet)$ and $\mathrm{AChE}(\boldsymbol{\square})$ in the rat diaphragm as a function of time at $37^{\circ} \mathrm{C}$. Arrows indicate the time at which prostigmine $(30 \mu \mathrm{M})$ was added to the medium. Details about the presentation of the results are given in the legend to Fig. 1.

decrease in spontaneous quantal release of ACh. In the same figure it can be seen that the addition of prostigmine in the reaction mixture, after $20 \mathrm{~min}$ of $\mathrm{Li}^{+}$action, caused a progressive disappearance of AChE activity of the rat homogenated diaphragm. Similar results were observed with lower concentrations of $\mathrm{LiCl}(86.4$ or $57.6 \mathrm{~mm})$.

At room temperature, when prostigmine was added simultaneously with the complete substitution of $\mathrm{LiCl}$ for $\mathrm{NaCl}$, the final effect on m.e.p.p. frequency was dependent on prostigmine concentration (Fig. 5, inset). Thirty $\mu \mathrm{M}$ of prostigmine caused the blockade of any rise in m.e.p.p. frequency. Using lower concentrations of prostigmine, the time course of m.e.p.p. frequency showed an initial increase to a maximum, which was followed by a decrease until the complete disappearance of m.e.p.p.s. The time of m.e.p.p. disappearance as also the maximum value of m.e.p.p. frequency $\left(F_{\max }\right)$ observed in the presence of $\mathrm{Li}^{+}$and prostigmine, decreased when prostigmine concentrations rose (Fig. 5). As can be seen in the inset of Fig. 5 , the time required for $F_{\max }$ depended also on prostigmine concentration. Therefore, the time constant $\tau$, during exposure of the rat neuromuscular junction to $\mathrm{Li}^{+}$, appeared prostigmine concentration dependent. The addition of prostigmine, at room temprature, was also effective for lower concentrations of $\mathrm{LiCl}$ ( 86.4 or $57.6 \mathrm{~mm}$ ) while its action seems also dependent on the percentage of substitution. Temperature influence was also significant during these experiments and the above results were more prominent at $37^{\circ} \mathrm{C}$.

Fasciculations, appearing at the rat diaphragm after prostigmine addition, were 


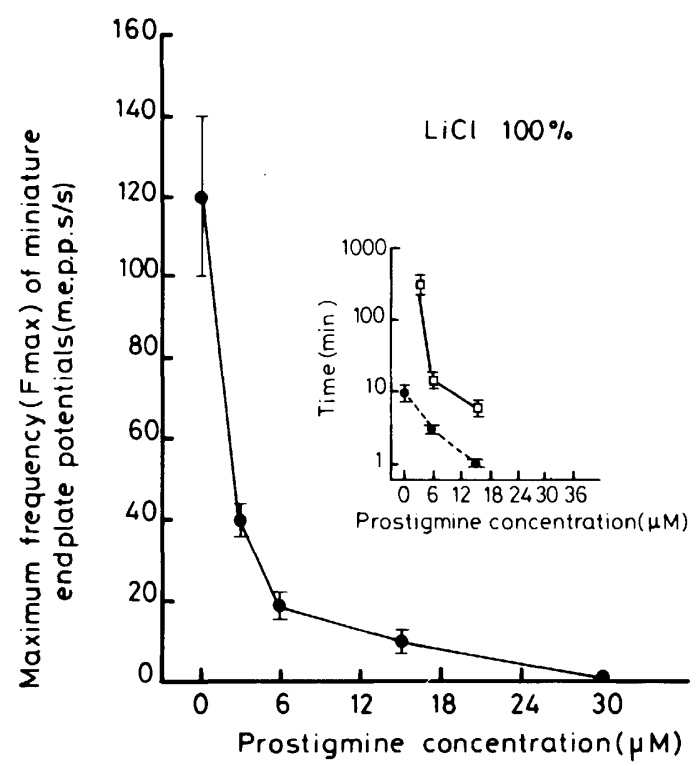

Fig. 5. Effect of prostigmine on spontaneous quantal release of $\mathrm{ACh}$ during exposure of the rat diaphragm to lithium. Prostigmine was added simultaneously with the substitution of $\mathrm{LiCl}$ for $\mathrm{NaCl}$ in $\mathrm{Krebs}$ solution and the experiments were performed at room temperature. Abscissa denotes prostigmine concentrations (in $\mu \mathrm{M}$ ) and ordinate the maximum frequency $(\bullet)$ of m.e.p.p.s (in m.e.p.p.s/s). Inset shows the prostigmine concentration dependence of the time needed for the appearance of $F_{\max }(\bullet)$ and of the time during which m.e.p.p. disappeared from the rat neuromuscular junction treated with $\mathrm{Li}^{+}(\square)$. Note the semilogarithmic coordinates.

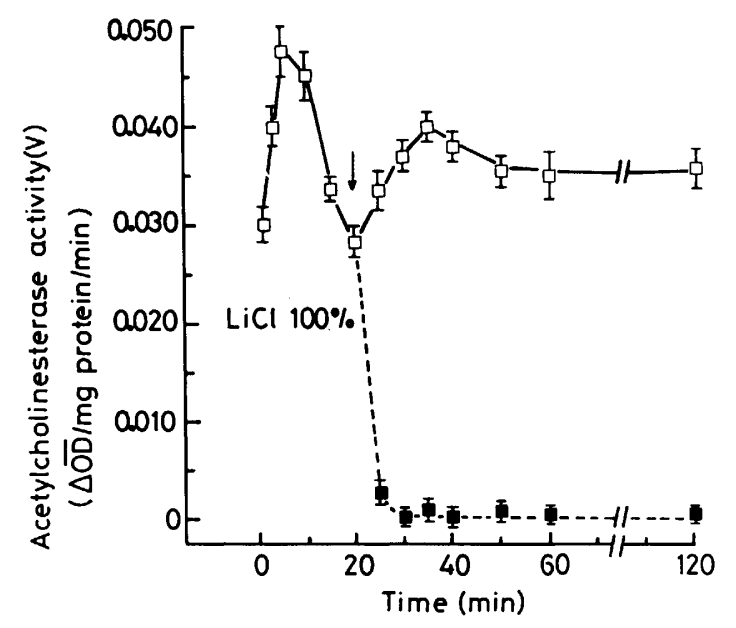

Fig. 6. Lithium action on $\mathrm{AChE}$ activity of the eel E. electricus pure $\mathrm{AChE}$ in relation to the time, in the presence $(\square)$ or absence $(\square)$ of prostigmine. Arrow indicates the time when prostigmine was added to the medium. For details see the legend to Fig. 1. 
observed even during exposure of the rat neuromuscular junction to $\mathrm{Li}^{+}$. However, in this case, the fasciculation appearance concerned almost exclusively the prostigmine concentration of $3.0 \mu \mathrm{M}$ as also the time until synaptic transmission blocking induced by $\mathrm{Li}^{+}$. Therefore the addition of tetrodotoxin is indispensable only during this phase of electrophysiological experiments.

\section{Time dependence of $\mathrm{Li}^{+}$effect on eel E. electricus $A C h E$}

Time dependence of $\mathrm{Li}^{+}$action was also observed on eel E. electricus AChE (see Fig. 6) and the time course of the enzyme activity was similar to the one observed in the case of diaphragm homogenate.

The action of prostigmine was more pronounced on the E. electricus AChE than on the AChE of the rat diaphragm homogenate.

\section{DISCUSSION}

In the present study, $\mathrm{Li}^{+}$was found to induce changes in $\mathrm{AChE}$ activity as a function of time. These changes did not appear during $\mathrm{Na}^{+}$action on the enzyme. The variations of $\mathrm{AChE}$ activity induced by $\mathrm{Li}^{+}$were observed in experiments with homogenized rat diaphragm as well as with pure eel E. electricus AChE. Moreover, the addition of prostigmine, which inhibits AChE activity, caused the disappearance of the above changes. The results reported in this study provide arguments for correlations between spontaneous quantal release of ACh and $\mathrm{AChE}$ activity at the rat neuromuscular junction under $\mathrm{Li}^{+}$action. So, one might speculate on the advantages of changes of $\mathrm{AChE}$ activity induced by $\mathrm{Li}^{+}$.

It is known that large changes in $\mathrm{Na}^{+}$concentration of bath solution can alter $\mathrm{Ca}^{2+}$ concentration in nerve terminal and $\mathrm{Li}^{+}$, acting as a substitute of $\mathrm{Na}^{+}$in the action potential, cannot replace $\mathrm{Na}$ ions in trasmitter release (GAGE and QUASTEL, 1966). However the alteration of m.e.p.p. frequency, during the substitution of $\mathrm{LiCl}$ for $\mathrm{NaCl}$, could not be attributed only to the changes in $\mathrm{Na}^{+}$concentration in the bath solution. In addition to the reasons supporting this view, we can include the following facts. 1) In our experiments partial substitution of $\mathrm{LiCl}$ for $\mathrm{NaCl}$ can increase m.e.p.p. freqeuncy even at low percentages. It should be noted that all our experiments were performed in solutions with normal concentrations of $\mathrm{KCl}$. Under the same experimental conditions the effects of lowering $\mathrm{Na}^{+}$, observed by GAGE and QuASTEL (1966), were much less and it was difficult to determine whether significant effects had occurred. 2) In experiments in which $5.9 \mathrm{~mm}$ of $\mathrm{NaCl}$ were substituted by $\mathrm{KCl}$ (KouNiniotou-KronTIRI, 1985b) the enhancement of m.e.p.p. frequency induced by $\mathrm{Li}^{+}$responded to changes in $\mathrm{K}^{+}$in the same way as was caused by glucosides (BIRKS and CoHEN, 1968). This is consistent with results showing the inhibitory action of $\mathrm{Li}^{+}$on diaphragm $\left(\mathrm{Na}^{+}, \mathrm{K}^{+}\right)$-ATPase (TsaKIRIS and Kouniniotou-KrontiRI, 1987). Moreover, what is important in determining the increase in m.e.p.p. frequency, during tetanization, is the number of pulses in the tetanus and not their frequency (CRAWFORD, 1975). Thus, m.e.p.p. frequency 
seems to be dependent on $\mathrm{Li}^{+}$entry into the nerve terminals; the accumulation of $\mathrm{Li}^{+}$within the terminals would be expected to cause increase in cytoplasmic $\mathrm{Ca}^{2+}$, responsible for the rise of m.e.p.p. frequency (CARMODY and GAGE, 1973; CraWford, 1975; OrTiZ and Junge, 1978).

However, the results of this study suggest that the exponential enhancement of m.e.p.p. frequency could be also related to the initial increase of AChE activity, at least in high concentrations of $\mathrm{LiCl}$. This view is supported by: 1) the coincidence in time between the exponential acceleration of m.e.p.p. frequency and the initial increase of $\mathrm{AChE}$ activity induced by $\mathrm{Li}^{+}$,2) the prostigmine concentration dependence of the maximum frequency of m.e.p.p., and 3) the blockade of the rise in m.e.p.p. frequency by prostigmine at the concentration of $30 \mu \mathrm{M}$, able to block in the presence of $\mathrm{LiCl}$ the diaphragm-associated $\mathrm{AChE}$ almost instantaneously. Moreover recent results showed that, during $\mathrm{Li}^{+}$action, a significant decrease of the m.e.p.p. time to peak appears at a time coinciding to AChE activation induced by $\mathrm{Li}^{+}$, while, at the same time there is no change of m.e.p.p. time to peak at neuromuscular junctions treated with $\mathrm{Li}^{+}$and prostigmine (KoUNINIOTOU-KRONTIRI, 1989). The decline of m.e.p.p. amplitude, observed during this phase, is not related to the membrane potential change and could be attributed to desensitization of ACh receptors and/or to the appearance of subminiature end-plate potentials (Kouniniotou-Krontiri, 1985a). The contribution of AChE stimulation to the above decline of m.e.p.p. amplitude is not clear because the same phenomenon was observed even in the presence of prostigmine (KouNINIOTOU-KRONTIRI, 1985a).

Since an important proportion of choline used for acetylcholine synthesis is derived from previously released acetylcholine (TUČEK, 1984), the decline of AChE activity could influence acetylcholine spontaneous quantal release by diminishing the choline uptake. So, the exponential decrease of m.e.p.p. frequency, observed in high concentrations of $\mathrm{LiCl}$, could be related to the decline of the enzyme activity, which was observed simultaneously. Furthermore, the inhibition of AChE activity by prostigmine addition during this phase caused an exponential decrease of m.e.p.p. frequency until a complete disappearance of miniatures. The decrease in m.e.p.p. frequency is not associated with reduction of m.e.p.p. amplitude. On the contrary, as has been reported (KoUNINIOTOU-KRONTIRI, 1985a), during this phase a transitory rise of m.e.p.p. amplitude can be observed. The above increase of m.e.p.p. amplitude cannot be explained by appearance of "giant" miniatures, the presence of which at the rat neuromuscular junction did not seem to be related to $\mathrm{Li}^{+}$action on the transmitter release (KouNINIOTOU-KronTIRI, 1985a). On the contrary, a relation between the transitory rise of m.e.p.p. amplitude and the observed decline of AChE activity could not be ruled out.

An increased final activity of the enzyme (Fig. 1) could contribute to the maintenance of a high final frequency of m.e.p.p.s $\left(F_{\mathrm{f}}\right)$ at the rat neuromuscular junction treated with high concentrations of $\mathrm{Li}^{+}$. This point of view can be supported by the following data: 1) the externally applied choline is accumulated mostly by a high affinity, sodium-coupled, transport system and depolarization of presynaptic 
terminals can accelerate choline uptake and ACh synthesis (VACA et al., 1982; TUČEK, 1984); 2) the depolarization of nerve terminals attributed to $\mathrm{Li}^{+}$accumulation (CRAWFORD, 1975), can also produce the above acceleration. Under these conditions, the role of an accelerated ACh hydrolysis seems to be important, because choline uptake by the presynaptic terminals appeared sufficient to maintain a high flow of ACh release even after a complete substitution of $\mathrm{LiCl}$ for $\mathrm{NaCl}$ (KouNINIOTOUKRONTIRI, 1985a). On the contrary, after prostigmine addition the final high level of m.e.p.p. frequency cannot be maintained and decreased exponentially until a complete disappearance of miniatures. Since our main interest was the possible correlation between $\mathrm{AChE}$ activity changes and spontaneous quantal release of $\mathrm{ACh}$, during exposure of the neuromuscular junction to $\mathrm{Li}^{+}$, effects on the post-synaptic membrane as the desensitization were not measured. However, in view of the fact that the m.e.p.p. amplitude was not reduced during the exponential decrease of m.e.p.p. frequency in the presence of $\mathrm{Li}^{+}$and prostigmine, the m.e.p.p. disappearance is unlikely to be caused by desensitization of $\mathrm{ACh}$ receptors. Moreover, under the same experimental conditions, choline addition to the medium is able to restore a high level of m.e.p.p. frequency (KoUNINIOTOU-KRONTIRI, 1985a).

Finally, a correlation between the rise of the maximum and final value of m.e.p.p. frequency with temperature and temperature effect on the time course of AChE activity could not be entirely ruled out.

In conclusion, the weight of evidence supports that the enzyme function, during $\mathrm{Li}^{+}$action, is an efficient means of ACh disposal at the synapse.

This work was supported by University of Athens.

\section{REFERENCES}

Birks, R. I. and CoHEN, M. W. (1968) The influence of internal sodium on the behaviour of motor nerve endings. Proc. R. Soc. B., 170: 401-421.

CADE, J. F. J. (1949) Lithium salts in the treatment of psychotic excitement. Med. J. Aust., 36: 349-352.

Carmody, J. J. and Gage, P. W. (1973) Lithium stimulates secretion of acetylcholine in the absence of extracellular calcium. Brain Res., 50: 476-479.

ChandLeR, W. K. and Meves, H. (1965) Voltage clamp experiments on internally perfused giant axons. J. Physiol. (Lond.), 180: 788-820.

Crawford, A. C. (1975) Lithium ions and the release of transmitter at the frog neuromuscular junction. J. Physiol. (Lond.), 246: 109-142.

Ellman, G. L., Courtney, D., Andres, V., and Featherstone, R. M. (1961) A new and rapid colorimetric determination of acetylcholinesterase activity. Biochem. Pharmacol., 7: 88-95.

GAGE, P. W. and QuASTEL, D. M. J. (1966) Competition between sodium and calcium ions in transmitter release at mammalian neuromuscular junctions. J. Physiol. (Lond.), 185: 95-123.

Hodgkin, A. L. and Katz, B. (1949) The effect of sodium ions on the electrical activity of the giant axon of the squid. J. Physiol. (Lond.), 108: 37-77. 
HuXLEY, A. F. and StÄMPfLI, R. (1951) Effect of potassium and sodium on resting and action potentials of single myelinated nerve fibres. J. Physiol. (Lond.), 112: 496-508.

Kelly, J. S. (1968) The antagonism of $\mathrm{Ca}^{++}$by $\mathrm{Na}^{+}$and other monovalent ions at the frog neuromuscular junction. Q.J. Exp. Physiol., 53: 239-249.

Kouniniotou-KrontiRI, P. (1985a) Effects du lithium sur la libération quantique spontanée de transmetteur par les terminaisons motrices du diaphragm de rat. J. Physiol. (Paris), 80: $340-348$.

Kouniniotou-KrontiRI, P. (1985b) Effect of $\mathrm{K}^{+}$on the frequency of miniature end-plate potentials during exposure of the rat neuromuscular junction to lithium. IRCS Med. Sci., 13: 432-433.

Kouniniotou-Krontiri, P. (1989) Changes in the time course of miniature end-plate potentials during the exposure of rat neuromuscular junction to $\mathrm{Li}^{+}$. Med. Sci. Res., 17: $247-249$.

Kouniniotou-KrontiRI, P. and TsakiRIS, S. (1984) Direct effect of lithium on acetylcholinesterase of the rat diaphragm. IRCS Med. Sci., 12: 1081-1082.

Lowry, O. H., Rosebrough, N. J., Farr, A. L., and Randall, R. J. (1951) Protein measurement with the Folin phenol reagent. J. Biol. Chem., 193: 265-275.

ONODERA, K. and YamaKaWA, K. (1966) The effects of lithium on the neuromuscular junction of the frog. Jpn. J. Physiol., 16: 541-550.

OrTIZ, C. L. and JUNGE, D. (1978) Depressant action of lithium at the crayfish neuromuscular junction: Pre- and postsynaptic effects. J. Exp. Biol., 75: 171-187.

Overton, E. (1902) Beiträge zur allgemeinen Muskel und Nervenphysiologie. Pfiügers Arch. Gesamte Physiol., 92: 346-386.

TSAKIRIS, S. and Kouniniotou-KrontiRI, P. (1987) Involvement of sulfhydryl groups in the inhibition of diaphragm $\left(\mathrm{Na}^{+}, \mathrm{K}^{+}\right)$-ATPase by lithium. Med. Sci. Res., 15: 697-698.

TsakiRIS, S. and Kouniniotou-KronTIRI, P. (1988) Changes in the cooperativity of diaphragm-associated acetylcholinesterase induced by monovalent $\left(\mathrm{Na}^{+}, \mathrm{Li}^{+}\right)$ cations. Biochem. Cell Biol., 66: 382-388.

TUCĚK, S. (1984) Problems in the organization and control of acetylcholine synthesis in brain neurons. Prog. Biophys. Mol. Biol., 44: 1-46.

VaCa, K., Johnson, D., and Pilar, G. (1982) Modulation of transmitter synthesis and release in cholinergic terminals. J. Physiol. (Paris), 78: 385-391. 